\title{
Export-Oriented Industrialisation and Dependent Development: the Experience of Singapore
}

\section{Cheah Hock Beng}

\section{Introduction}

Development which relies in varying degrees upon the export of manufactured goods is not a new phenomenon. It was in many ways significant in the early development experiences of a number of the advanced industrial countries. Indeed, stressing the role of exports and the importance of the foreign trade multiplier, Kaldor [1977| has argued that the growth of all rapidly industrialising countries has been export-led.

The most recent school to advocate export-oriented industrialisation (EOI) as the appropriate strategy for the developing countries has sought its justification not so much in the historical experience of the earlier industrialisers as in the reputed failures of importsubstituting industrialisation (ISI). In general, this school has a theoretical and policy perspective associated with the orthodox growth-and-modernisation approach to development, and it sees EOI as the strategy through which a Rostow-type development process could be initiated and sustained in the developing countries, where ISI failed / see Keesing 1967; Little. Scitovsky and Scott 1970; Balassa 1971; Myint 1972; Johnson 1973; ILO 1974; and Little 1979].

The proponents of the EOI strategy argue that it would promote a form of industrialisation which would be more efficient and internationally competitive, and more in tune with the employment needs of developing countries, because it would be concerned with developing production in lines in which these countries have an obvious comparative advantage, namely, labourintensive manufactures. Starting on these lower rungs of manufacturing, these countries could, over time, progress towards more sophisticated manufacturing activities. All this would go along with the opening up of the economy, greater reliance on the free-market price mechanism, the elimination of impediments on trade, investments and other financial flows, and generally increased integration with the international economy.

However, the critics of this strategy allege it has high economic and social costs, such as the increasing dependence of the economies concerned and the growing exploitation of their labour-forces, and argue against both the desirability and the likelihood of the long-term success of the strategy. The main force of their arguments is that the EOI strategy has served to promote an influx of foreign investment, mostly by metropolitan multinational companies (MNCs) which have generally established processing and assembly plants, utilising cheap local labour for largely unskilled and labour-intensive parts of the production process. Such production is generally based upon the import of most or all of the key manufacturing inputs (with high value added operations and $R$ and $D$ activities confined to the metropoles), in operations which are externally vertically integrated. The general consequence is that minimal benefit (in terms of local linkages, local learning and local control of the production process) accrues to the developing country involved, while maximum advantage accrues to the MNCs (in terms of control over production, pricing, profits and general economic leverage over the local labour force and the local state) |see Sutcliffe 1971, pp 270-80; Helleiner 1973; Trajtenberg 1976; AMPO 1977; Nayyar 1978; and Fröbel, Heinrichs and Kreye 1980|.

This paper seeks to draw out the implications of the experience of the EOI strategy in Singapore for these opposing views and in particular, to assess the extent to which it challenges the dependency approach.

\section{Development Strategy: the Context and the Policies Adopted}

Development efforts in Singapore should be viewed in the context of a relatively new and very vulnerable political entity, attempting to establish a place for itself in an unstable and changing world $-a$ small island city-state which has sought to overcome the immense domestic and external pressures impinging upon it through undertaking the most rapid form of development open to it. With a population of only about two million, a land area of only $616 \mathrm{sq} \mathrm{km}$, resulting in high population density and strong pressures on employment opportunities, it has traditionally been dependent on trading and other service activities and on imports of energy resources, raw materials and food for its population and production activities. Despite the rapid growth of industry, the tertiary sector as a whole continues to be the dominant economic sector.

Following the break from Malaysia in 1965 the citystate was left with only its small domestic market. The economic strategy (up to this point largely ISI) was consequently modified to emphasise export-oriented industries that would cater for the general world market. The MNC then seemed to be an ideal ally in 
this regard, because it had the technical expertise which could help to raise local skills, its labourintensive operations would create substantial employment, and it had established access to foreign markets. Moreover, the entrenchment of foreign capital, expertise and other supporting institutions in the country would ensure external interest in the survival and continued growth of the city-state. Consequently, the main thrust of the economic strategy was to integrate the domestic economy more closely with the international economy, with the associated aim of maximising the rate of economic growth.

The policies associated with this strategy involved offering fiscal incentives, providing an extensive and modern infra-structure, redefinition of the contractual relationship between employers and employees, imposition of restraints upon the local labour movement, the import of foreign labour, and a general policy of wage restraint. There was an acceptance of the fact that foreign investors are primarily profit-seeking. The concessions provided were justified by reference to the employment opportunities and the access to developed country markets provided, in particular by the MNCs.

Less attention and support was provided to the generally smaller local firms and industries, because they were mainly engaged in processing and repairing activities not oriented towards export. Insofar as these local industries harboured a significant proportion of the labour force while the new industries encountered increasing labour shortages, justifications were found to eliminate, directly or indirectly, many of the local establishments and to rationalise the rest to be more in tune with the overall industrialisation strategy.

An important aspect of the problem was that the citystate had not traditionally had as strong an involvement in manufacturing as, for instance, Hong Kong. This posed serious difficulties for any indigenous efforts to develop a significant and internationally competitive manufacturing sector in the short or. medium term. Instead, it was thought that an 'open-door' policy would be more successful-despite its costs. And, based upon a realistic assessment of the difficulties involved in acquiring and developing sophisticated technology, an equally pragmatic approach was formulated for the longer-term development of domestic technical skills at the same time as immediate opportunities were exploited for the application of intermediate skills [see Geiger and Geiger 1975:24-5].

The general strategy was formulated and implemented in a period when developed country economies were still experiencing relatively high rates of growth. The initiation of the strategy also coincided with growing competition between major US European and Japanese firms, and increasing US direct foreign investment. These investments were directed largely towards Europe, to take advantage of the relatively more rapid growth rates, lower wages and higher productivity, to expand the total world market share of US firms and also to hedge against decline in the value of the US dollar. However, many subsidiaries were also established in a number of developing countries, to benefit from the cheaper cost of labour, employed in processing and assembly activities vertically integrated into the broader international operations of US MNCs, so as to acquire a competitive edge over European and Japanese firms.

The response of European and Japanese firms to this challenge from US companies has been varied, but it also includes more direct foreign investment on their part and the transfer of certain production activities to a number of developing countries-not so much to expand market shares in those areas themselves (as previously) but rather to follow US MNCs into externally vertically integrated production processes capitalising upon cheaper labour sources. These, then, were the conditions under which the introduction and rapid growth of export-oriented manufacturing occurred in Singapore and, with some variations, in a number of other Asian countries.

\section{Structural Change in Manufacturing and Associated Developments}

In 1965, direct exports of manufactures from Singapore constituted only 32 per cent of total sales value in the manufacturing sector. If the criterion for an exportoriented industry is taken as direct exports accounting for 50 per cent or more of total sales, only four industry groups qualified as such. They were textiles (including wearing apparel) and footwear (SSIC 23+24), leather products (SSIC 29), rubber products (SSIC 30), and electrical machinery (SSIC 37). Together, these four industry groups contributed only about 17 per cent of all direct manufactured exports. The greater part of direct manufactured exports was contributed by other industries which were primarily catering for the local market. The relative insignificance of the export industries at this time is further evidenced by the fact that they accounted for only about 14 per cent of all manufacturing establishments, 19 per cent of the labour force and 9 per cent of the net value of fixed assets in the sector. They also contributed only 8 per cent of total output and about 9 per cent of all value added in manufacturing.

The experience during the transitional period 1965-68 showed the existence of serious constraints on export markets for developing country manufactures in the 
area of standard light consumer products, such as those that characterised Singapore's export industries in 1965. The potential for rapid and sustained industrialisation on this pattern was limited by restrictions on access to developed country markets, barriers posed by import-substituting policies in other developing countries, and not least, by the prior entrenchment of other export-oriented developing countries like Hong Kong and Taiwan in these lines of production.

Between 1968 and 1974 there was a boom in the export industries, based on a diversification into electronics, precision instruments, shipbuilding and repairing, oil-rig construction, and a major expansion of petroleum refining. These developments were part of the influx of foreign investment and the proliferation of MNC subsidiaries. During this period, wholly foreign firms contributed 45 per cent of the increase in the number of workers employed in manufacturing, 63 per cent of the growth in output, and 53 per cent of the growth in value added.

In this period the export industries came to dominate all the significant aspects of manufacturing, reversing their position $v i s-\grave{a}-v i s$ the domestic-oriented industries in the earlier phase. They grew at very rapid rates and contributed about 90 per cent or more of the total increase in employment, wages, fixed assets, output, value added, subcontracted production, total sales and direct exports. The experience during this period showed the vast potential for growth in manufactured exports based on a more diversified industrial structure.

The number of industry groups oriented towards export increased from 3 in 1968 to 11 in 1974. These developments in manufacturing brought about significant changes in the content and composition of trade. Where direct exports accounted for only 33 per cent of total sales in 1965, the ratio was 65 per cent in 1978 . Between 1965 and 1978 the value of direct exports increased 36 times.

Since 1969, domestic manufactures have accounted for more than half of all domestic exports and the earlier tradition of entrepôt trade was transcended in 1974 when domestic exports exceeded re-exports. By 1978 foreign dominated firms accounted for 52 per cent of the workers employed, 71 per cent of total output, 6.3 per cent of all value added, 53 per cent of employees' remuneration, 72 per cent of total sales and 84 per cent of direct exports from the sector.

While foreign firms have been the most important in export-manufacturing activities, the increasing importance of local firms in export industries should also be noted. Where in 1968 only 15 per cent of wholly local firms were involved in export-oriented industries, the proportion had risen to 44 per cent in 1978. While wholly local firms were themselves responsible for only 8 per cent of direct manufactured exports in 1978, compared to 71 per cent by wholly foreign firms, the extent of their increased involvement in the export industries suggests that important linkages may have developed between local and foreign firms. This association may be significant, even though the total proportion of subcontracted production in the export industries is very low, because the absolute values involved are quite substantial. For instance, while total subcontracted production for all export industries in 1978 was only 2 per cent of output, it amounted to S\$299.5mn.

This general transformation of manufacturing provided the basis for the rapid growth of the sector as a whole. The contribution of manufacturing to total GDP increased from 15 per cent in 1965 to 26 per cent in 1977. Over 1968-78, its real contribution to GDP grew at an average annual rate of 24 per cent, while total GDP grew by 15 per cent in corresponding real terms. For the economy as a whole, GDP at constant (1968) factor cost grew at an average annual rate of 11 per cent from $\$ \$ 2,780 \mathrm{mn}$ in 1965 to $\$ \$ 10,089 \mathrm{mn}$ in 1978 . In 1978 indigenous GNP(S\$13,979mn) was 20 per cent less than overall GNP at current market prices (S\$17,423 mn). Although these differences are certainly significant, they seem much smaller than what might be expected from the manner and extent of the citystate's pursuit of the EOI strategy.

The number of manufacturing establishments employing 10 or more workers almost trebled in the period 1965 . 78 , while the number of workers employed increased five-fold. During the same period, female employment increased 8.5 times, compared to a three-fold increase in male workers. At the same time, output increased 18 times while value added and net fixed assets both grew about 13 times. By 1974, manufacturing had replaced commerce as the category of economic activity providing the most employment.

Despite the generation of a large amount of low wage and particularly female employment and the import of large numbers of foreign workers, the high rates of growth of the export industries after 1968 helped to transform a labour surplus' situation into one of relative labour scarcity. The official unemployment rate for the whole economy declined from 9 per cent of the labour force in 1965 to less than 4 per cent in 1978, despite the fact that the labour force had grown from 557,000 to 975,000 and the participation rate had also increased from 55 to 6.3 per cent during that period. 
In addition to manufacturing, there have been other important growth sectors in the economy. These include banking and finance, transport and communications and other service activities. Although developments in these areas may be less notable, they are nevertheless quite significant. These areas of activity were, in many cases, relatively easier for local entrepreneurs to venture into and to operate quite profitably within, even in the face of direct or indirect foreign competition. Local interests had been able to profit from local knowledge, local associations and access to privileged operating conditions, so as to make these activities the bases for local capital accumulation. These bases have grown over time and in a number of cases have expanded beyond domestic operations, with local firms internationalising their own operations to a significant degree. In this regard, an important development is the growing role of state enterprises in the economy.

The combined result of these and other developments has been a more diversified economic structure. The city-state has been transformed from a primarily entrepôt trading centre prior to 1965 , to a centre of manufacturing, commercial, financial, transport and communications activities at present. The diversification of the economy has contributed, on the one hand, to a more stable domestic economy as the fluctuations in any individual sector are partly balanced by compensating developments in other sectors; and on the other hand, to an increasing intermeshing and mutual stimulation of the different economic sectors. All this contributes to a general climate of dynamism and growth in the economy, which, although still very much affected by external influences, yet manifests a certain degree of autonomy in its operations.

There has also been a general improvement in the standard of living. Education and training opportunities have rapidly expanded, and the massive public housing programme now provides accommodation for about 60 per cent of the population. While there remains room for further improvement in the social services in relation to the needs of the poor, recent estimates suggest that there has been a marked decline in the general level of absolute poverty. Moreover, although equity was not a major objective of the economic strategy, various studies suggest that there has been some improvement in the general pattern of personal income distribution.

These changes in the economy and society as a whole suggest that the room for development in this very dependent city-state, for the period reviewed, has been wider than the critics of the general strategy perceived it to be [see Buchanan 1972]. The achievements also indicate the important degree to which domestic policies, institutional arrangements and leadership may be able to influence and extend that scope. For despite its vulnerability, Singapore has been able to develop and adapt to change to a greater extent than its mere size and resource base seemed to allow.

\section{Problems and Prospects}

If dependence and underdevelopment are not necessarily associated, in the manner postulated by many of the critics of the EOI strategy, neither are (continuing) growth and development as definite an outcome of the strategy as its advocates imply. In Singapore, the export industries in particular, and the manufacturing sector in general, experienced a decline in 1974-75. Subsequently, there has been a recovery, but with growth rates significantly below those achieved in the period 1968-74. These developments were due to the emergence of serious external and domestic constraints.

The onset of the general international recession has changed the situation significantly. It marked the end of the previous phase of rapid growth of the developed country economies and the intensification of competitive pressures between countries and firms. Reduced growth and technological development towards fully automated production processes in advanced industrial countries are also tending to diminish the industrial servicing role of Singapore and other developing countries. In addition, there has been a significant change in general climate for the EOI strategy, given increased pressures by trade unions in the West against the 'export of jobs' to new industrialising countries, complaints by various developed country producers about 'unfair competition' and associated demands for import restrictions, and a growing criticism of low-wage export-oriented industrialisation as a general strategy for the developing countries.

Yet another worrying consideration is the extent to which competitive pressures may build up between various developing countries as a direct consequence of their common pursuit of the strategy, which may lead them, in effect, to pit their respective low-wage labour forces against one another. Certain changes may also seriously undermine the principal basis of Singapore's EOI strategy, such as the IMFs recent attempt to reclassify Singapore as a 'developed' country. Among other things, the effect would have been to exclude the city-state from access to various export markets and official financial credits under preferential terms.

Other problems arise from the inadequate extent of domestic linkages in manufacturing and from the fact that foreign firms have not promoted locally-based 
technological developments. In addition to foreign capital being dominant in manufacturing and providing the major part of its exports, these exports generally involve a very high level of intra-firm trade. This implies that the city-state pays a higher price, relative to more independent producers, for the inputs associated with the closely MNC-integrated structure of its manufactured exports. It also means its exports are to some extent shielded from developed country restrictions set up to restrain the penetration of independently promoted manufactured exports.

However, the earlier boom in the export industries and their recent resurgence have revealed a major domestic labour constraint on the continued pursuit of the strategy. They have encountered increasing labour shortages, initially for skilled male workers, but eventually also for unskilled and low-wage female production operatives, at current rates of remuneration. Upward pressures on wage rates have tended to make some export industries less competitive than those of other developing countries. The problem was earlier partly resolved by the import of temporary foreign workers. However, a continuation of this would soon increase their numbers immensely relative to the citystate's indigenous population and labour force, and intensify general population pressures. For the labour shortage has increasingly become a structural problem for the economy as a whole | see Ker 1977|. Moreover, the general policy of wage restraint has tended to compound these problems, serving to entrench the less productive and lower growth economic sectors and discouraging the more productive and higher growth sectors [see Pang 1979].

These developments together suggest a need, over the medium term, for the city-state to diversify away from export-oriented manufacturing in its present form, if a relatively high rate of growth is to be sustained in the economy. The perception of this has led the government to make a variety of responses. It has sought to attract even more foreign investment by shifting incentives into production involving more technologically sophisticated manufacturing operations-an upgrading of the earlier strategy. The general objective is to promote the manufacture of selected high value added products and skill-intensive operations in which the country might have sufficient comparative advantage. In support, greater attention and resources are being allocated to the promotion of local technological development.

A recent major policy initiative reversing the previous policy of general wage restraint, aims to further this structural shift to a more productive and higher-wage economy / see Far Eastern Economic Review, 10 August 1979:40-44]. With the new economic policy, it is envisaged that low-wage, low-skilled and low value added operations would be phased out by the deliberately increased labour costs, while employers would be motivated to economise on labour through organisational rationalisation and general restructuring of production. It is thought that this policy wilhclear the bottlenecks on productivity increases and on the general upgrading of skills, which would constitute the new bases for international competiveness.

The outcome of these measures is as yet uncertain. Much will depend on the strategies and policies adopted in other countries and among firms, particularly the MNCs, in response to continuing recession and growing international competitive pressures.

\section{Conclusion}

Various domestic and external constraints on Singapore led it to adopt the EOI strategy. Its development experience since 1965 has served as a test of both the possibilities and the limits of the strategy.

To the extent that Singapore has become more closely integrated into the international economy, it is increasingly subjected to the pressures and strains generated within that system. At the same time, however, various changes occurring within that system provide new opportunities for it. Furthermore, as a small island city-state, achievements and breakthroughs of less than global significance can be very important for it. So it could continue to find a suitable niche in the international division of labour to provide relatively high rates of growth and the basis for continued development, even under the present constrained economic situation. The earlier phase of the strategy provided the time and opportunity for the growth. diversification and upgrading of several sectors of the economy and the transformation of many aspects of the society.

Nevertheless, the constraints and pressures which the country faces are considerable. In attempting to establish an even more diversified, integrated and dynamic economy, capable of providing the basis for a higher general standard of living in the country, the leadership seems deeply conscious of the likely difficulties ahead. It has emphasised the sustaining of rapid adaptation to change, to keep ahead of emerging problems.

Between the general structural constraints and the specific policy options and practical initiatives that can still be undertaken, lie a whole range of cumulative and interactive effects and possible historically unique events, which prevent the longer term outcomes from being predetermined. Much of what would affect the city-state will originate abroad and will be beyond its 
capacity to control. but not entirely beyond its capacity to seek more or less positive adjustments in response. We are confronted by the reality of 'dependence' not as some frozen state. but as a generally constrained situation which is itself subject to change in various different ways. And this specific development experience suggests that both the advocates and the critics of the EOI strategy were wrong. each differently. in a way that reveals the situation to be more complex for the late-developing countries than either group originally perceived.

First. the successes derived. directly and indirectly. from the adoption of EOI in Singapore are not as easily generalisable as many of those who wish to promote the model would suggest. The city-state had various advantages (among others. its location. the quality of its economic and social infrastructure. and the economic and political skills of its leadership) which helped its efforts at development through EOI. At the same time. other developing countries less constrained than Singapore. in resources. domestic markets and indigenous manufacturing capabilities. either do not need to adopt the EOI model. or not in the form or to the extent that Singapore has done.

Secondly. the advocates of the strategy overestimated the extent to which the international economy would be flexible. expansive and accommodating of manufactured exports from developing countries. Even the existing relatively low level of such exports has caused developed country interests to be alarmed and to press for various measures of restraint.

The advocates clearly failed to specify the general conditions on which the strategy depended. and failed to see that its appliçability would be restricted-suitable for particular countries during specific periods. They neglected the self-undermining elements in a process of change. failing to see that the very success of the strategy would. in certain ways. create new difficulties and constraints for the countries concerned.

However. the critics of the strategy were too pessimistic and neglected significant developments in the new industrialising countries. These developments and the implications of the perception in some quarters in the West of the 'threat' posed by the 'new Japans' have not been fully confronted.

From a historical perspective. the critics have also ignored the earlier development experiences of Japan and the other western industrialisers after Britain. classifying them as inherently a part of the 'centre'. and assuming that what was possible in the phase of competitive capitalism' is no longer possible in the phase of 'monopoly capitalism'. | For a critique of this thesis. see Clifton 1977 and Wirth 1977|.In this way. it could be contended - eg against Warren|1973|-that there has not been a real instance of the successful capitalist development of a peripheral country.

The critics of EOI have also largely approached the issues in general and global terms. without sufficient regard for the different phases of the international economy. the specificities of individual countries. and the contribution of specific organisational and institutional arrangements. Moreover. they generally operate with an ideal type. it not utopian. image of the development process. against which the realities of the experience of peripheral country development are consequently found wanting. They fail to give sufficient consideration to the specific possibilities and overgeneralise the perceived limits. They too ignore an important aspect of development processes. that is, the ongoing changes in the centre-periphery system. and the complex and uneven (rather than simple and unambiguous) character of economic and social transformation within and between countries.

While the reality and seriousness of the problems associated with dependence cannot be denied, the totality and conclusiveness of that experience cannot be maintained. The critics take too monolithic a view of international capitalism. overstate the sway of the MNCs. neglect the significance of domestic developing country constraints. and are unable or slow to detect qualitative changes in a general situation. Several of these difficulties are closely related to problems with the broader thesis. which overemphasises and overgeneralises the association between dependency and underdevelopment. For dependence. where it exists. is clearly not the only problem and may not always be the most serious impediment to development. Any assessment of the EOI strategy and its potential for development must involve a consideration of both the changing international context and the country-specific situations so as to provide a keener perception of possibilities and constraints during a specific period.

note: the more general dependency references are not given here but in the bibliography at the end of this Bulletin.

\section{References}

AMPO. 1977. ' Free trade zones and industrialisation of Asia'. Japan-Asia Quarterly Revien: Pacific-Asia Resources Center. Tokyo

Balassa. B.. 1971. 'Industrial policies in Taiwan and Korea'. Weltwirtschaftliches Archil. vol 106 no 1. 55-57

Buchanan. 1.. 1972. Singapore in Southeast Asia: an Economic and Political Appraisal. Bell and Sons. London 
Far Eastern Economic Review, 1979. Feature on Singapore. 10 A ugust

Geiger. T. and F. M. Geiger. 1975, The Development Progress of Hong Kong and Singapore, Macmillan. London

Ker. S. T.. 1977. 'A projection for labour demand and supply in Singapore to $1985^{\circ}$. Southeast A sian Journal of Social Science. vol 5 nos 1-2. pp 55-65

Lee. S. A.. 1973. Industrialisation in Singapore. Longman. Australia
Little. 1.. 1979. 'The experience and causes of rapid labour' intensive development in Korea. Taiwan. Hong Kong. and Singapore: and the possibilities of emulation: Working Paper no 1. ILO Asian Employment Programme

Myint. H.. 1972. Southeast Asia's Economy: Development Policies in the 1970s. Penguin. Harmondsworth

Pang. E. F., 1979. 'The labour market in Singapore: key issues and outlook'. Singapore Business Yearbook 1979. pp 37-43 